\title{
Resistance Potential of Colorado Potato Beetle (Coleoptera: Chrysomelidae) to Novaluron
}

\author{
Author(s): G. Christopher Cutler, Jeffrey H. Tolman, Cynthia D. Scott-dupree, \\ and C. Ronald Harris
}

Source: Journal of Economic Entomology, 98(5):1685-1693. 2005.

Published By: Entomological Society of America

DOI: 10.1603/0022-0493-98.5.1685

URL: http://www.bioone.org/doi/full/10.1603/0022-0493-98.5.1685

BioOne (www.bioone.org) is an electronic aggregator of bioscience research content, and the online home to over 160 journals and books published by not-for-profit societies, associations, museums, institutions, and presses.

Your use of this PDF, the BioOne Web site, and all posted and associated content indicates your acceptance of BioOne's Terms of Use, available at www.bioone.org/page/terms_of_use.

Usage of BioOne content is strictly limited to personal, educational, and non-commercial use. Commercial inquiries or rights and permissions requests should be directed to the individual publisher as copyright holder. 


\title{
Resistance Potential of Colorado Potato Beetle (Coleoptera: Chrysomelidae) to Novaluron
}

\author{
G. CHRISTOPHER CUTLER,,${ }^{1,2}$ JEFFREY H. TOLMAN,${ }^{3}$ CYNTHIA D. SCOTT-DUPREE, ${ }^{1}$ \\ AND C. RONALD HARRIS ${ }^{1}$
}

\begin{abstract}
J. Econ. Entomol. 98(5): 1685-1693 (2005)
ABSTRACT Novaluron (Rimon 10 EC), a novel insect growth regulator, could play an important role in future management programs for Colorado potato beetle, Leptinotarsa decemlineata (Say). Studies were conducted to determine the potential of Colorado potato beetle to develop resistance to novaluron before its widespread use in Colorado potato beetle management. Second instars of an imidacloprid-resistant Colorado potato beetle strain exhibited reduced susceptibility (2.5-fold) to novaluron. The toxicity of novaluron to this strain was synergized by S,S,S-tributyl phosphorotrithioate (DEF) but not by piperonyl butoxide (PBO), suggesting that esterase-based detoxification mechanisms were responsible for novaluron resistance. Bioassays with treated potato foliage found that a single low- or medium-rate novaluron application was highly persistent under field conditions, resulting in up to $85 \%$ mortality of second instars $5 \mathrm{wk}$ after treatment. Thus, intense selection pressure for novaluron-resistant Colorado potato beetle may continue long after population densities have been reduced below an economic threshold level. In a national survey, the susceptibility of second instars to a novaluron diagnostic dose was determined for 27 different field populations collected from six Canadian provinces in summer 2003. Despite no previous exposure to novaluron, mortalities at the diagnostic dose ranged from 55 to $100 \%$. Although novaluron has several characteristics that should delay resistance development in insect pests, these results highlight the need for judicious use of the compound in management of Colorado potato beetle.
\end{abstract}

KEY WORDS Leptinotarsa decemlineata, novaluron, resistance, persistence, synergism

INSECTICIDE RESISTANCE CONTINUES TO be an important problem in insect pest management. Georghiou (1986) reported resistance development in 447 species of insect and mites. Presently, at least 536 species have developed resistance to pesticides and $>300 \mathrm{ac}-$ tive ingredients have been subject to resistance by at least one insect or mite species (Whalon et al. 2004). The Colorado potato beetle, Leptinotarsa decemlineata (Say), is perhaps the agricultural insect pest most prone worldwide to development of resistance to insecticides (Bishop and Grafius 1996). The beetle has evolved resistance to at least 41 different active ingredients (Whalon et al. 2004). In Canada, resistance has developed to organochlorines (Harris and Svec 1976, McDonald 1976, Harris and Svec 1981), carbamates, organophosphorous insecticides, and pyrethroids (Harris and Svec 1981, Harris and Turnbull 1986, Boiteau et al. 1987). Since its emergency registration in 1995, imidacloprid (Admire $240 \mathrm{~F}$ ) has provided excellent Colorado potato beetle control for potato growers in Canada. However, in 2002 and 2003, per-

\footnotetext{
${ }^{1}$ Department of Environmental Biology, Ontario Agricultural College, University of Guelph, Guelph, Ontario, Canada, N1G 2W1.

${ }^{2}$ Corresponding author, e-mail: cutler@uoguelph.ca.

${ }^{3}$ Southern Crop Protection and Food Research Centre, Agriculture and Agri-Food Canada, 1391 Sandford St., London, Ontario, Canada, N5V 4T3.
}

sonnel in Agriculture and Agri-Food Canada detected the onset of potential imidacloprid resistance development in several Canadian Colorado potato beetle populations and strongly recommended incorporation of a new control agent in future management programs (Tolman et al. 2002, 2003). Imidacloprid resistance has developed in a number of U.S. Colorado potato beetle populations (Olson et al. 2000, MotaSanchez et al. 2000, Zhao et al. 2000).

Novaluron is a novel benzoylphenyl urea insecticide that exhibits insecticidal activity against several important foliage-feeding insect pests (Ishaaya et al. 1996, 2001, 2002). By inhibiting chitin formation, novaluron selectively targets larval insect stages. In studies with natural enemies, it had no effect on field populations of phytoseiid mites (Ishaaya et al. 2001), greenhouse populations, and percentage of parasitism of the parasitoid Encarsia formosa Gahan (Ishaaya et al. 2002), and mortality and development of Stratiolaelaps scimitus (Womersley), a soil-dwelling predatory mite (Cabrera et al. 2005). The prospects for novaluron in integrated pest management (IPM) programs are therefore considerable. Laboratory and field studies have shown that novaluron has insecticidal activity against Colorado potato beetle and has considerable potential in its management (Malinowski and Pawinska 1992; Linduska et al. 2001, 2002; 
Sewell and Alyokhin 2003; Cutler et al. 2004, 2005). However, considering its management history, resistance to novaluron could rapidly develop in Colorado potato beetle. All resistance mechanisms reported in insects have been documented in Colorado potato beetle (Bishop and Grafius 1996), and in the absence of selection pressure, insecticide-resistant Colorado potato beetle can retain resistance mechanisms (Bishop and Grafius 1996, and references therein; Tolman et al. 2002, 2003). Furthermore, the same resistance mechanism may confer resistance to both benzoylphenyl urea and conventional insecticides. Organophosphorous-, carbamate-, and organochlorine-resistant house flies have exhibited cross-resistance to diflubenzuron, the first registered benzoylphenyl urea insecticide (Cerf and Georghiou 1974, Oppenoorth and Van Der Pas 1977).

To assess the possibly of development of resistance by Colorado potato beetle to novaluron, a number of experiments were undertaken. Because imidacloprid is currently the insecticide most used for Colorado potato beetle control in Canada, the susceptibility of an imidacloprid-resistant Colorado potato beetle strain to novaluron, with and without synergists, was determined. Also, as insecticide persistence has been cited as a major factor in the development of resistance (Roush 1989), bioassays were conducted to determine the field persistence of biological activity of novaluron applied to foliage. Finally, variability in susceptibility to novaluron among representative populations of second instars was determined by measuring response to a diagnostic dose, a single insecticide concentration that will distinguish susceptible from resistant individuals.

\section{Methods and Materials}

Insects. Previous work indicates that novaluron field applications are most effective against Colorado potato beetle when targeted against second instars (G.C.C., unpublished data). Therefore, all tests were done using second instars. An insecticide-susceptible Colorado potato beetle strain reared for 50 generations on potato $\left(27^{\circ} \mathrm{C}, 65 \% \mathrm{RH}\right.$, and a photoperiod of 16:8 [L:D] h) at the Southern Crop Protection and Food Research Centre, Agriculture and Agri-Food Canada in London, Ontario (SCPFRC-London), Canada, was used as the reference strain. The imidacloprid-resistant strain, originally collected from Long Island, NY, in 1997, was obtained from E. Grafius and A. Byrne (Michigan State University, East Lansing, MI). Imidacloprid resistance in the Michigan population, $\approx 91$-fold in Colorado potato beetle adults compared with an insecticide susceptible strain, had been maintained through selection in the laboratory by exposing adult beetles topically to imidacloprid doses lethal to $60-80 \%$ of the population. This population also exhibited approximately four-fold adult resistance to thiamethoxam, another neonicotinoid insecticide (E. Grafius, personal communication). In the current study, $\mathrm{F}_{17}$ adults obtained from E.G. and A.B. were reared $\left(27^{\circ} \mathrm{C}, 65 \% \mathrm{RH}\right.$, and a photoperiod of $16: 8$
[L:D] h) in the absence of insecticide selection pressure. Larvae from the $F_{18}$ generation were used in experiments.

Twenty-seven field populations collected from six Canadian provinces-Prince Edward Island (four), Nova Scotia (one), New Brunswick (six), Quebec (six), Ontario (nine), and Manitoba (one)-were used in the survey of susceptibility to novaluron. Ontario populations were collected by personnel from the SCPFRC-London. Research or extension personnel collected Colorado potato beetle populations outside of Ontario. To optimize insect quality, standardized collection and shipping kits, each containing detailed instructions and a collection information sheet, were forwarded to each cooperator. All collections, consisting of 250-500 Colorado potato beetle adults, were received at SCPFRC-London and promptly transferred to oviposition cages containing 4-6-wk-old potted potato plants. Once oviposition began egg masses were collected daily, and larvae were reared through to the second instar (Harris and Svec 1976). All bioassays were conducted on second instars from the laboratory $F_{1}$ generation of each field collection.

Chemicals. Novaluron (Rimon 10 EC [novaluron $100 \mathrm{~g}$ [AI]/liter] and Rimon Technical [novaluron 96.0\% purity]) was supplied by Makhteshim-Agan of North America Inc. (Raleigh, NC). Formulated imidacloprid (Admire $240 \mathrm{~F}$ [240 g [AI] / liter] and technical grade [98.7\% purity]) was supplied by Bayer CropScience Canada Inc. (Calgary, Alberta, Canada). Synergists used were technical grade piperonyl butoxide (PBO) $(90.0 \%$ purity, Aldrich Chemical, Milwaukee, WI) and a $70.5 \%$ emulsifiable concentrate of S,S,S-tributyl phosphorotrithioate (DEF) (Bayer CropScience U.S., Research Triangle Park, NC).

Susceptibility of Imidacloprid-Resistant Colorado Potato Beetle. Residual leaf-dip bioassays on second instars were conducted to determine the susceptibility of the imidacloprid-resistant strain to novaluron (Rimon $10 \mathrm{EC}$ ) and imidacloprid (Admire $240 \mathrm{~F}$ ). Insecticides were each suspended in reverse-osmosis water to give a range of concentrations ranging from 0.001 to $10.0 \mathrm{ppm}$. As determined in preliminary tests, concentrations that caused 5-95\% mortality were used in bioassays. Four-centimeter-diameter discs were cut from potato leaves with a stainless steel cork borer. Discs were dipped in insecticide solution for $\approx 6 \mathrm{~s}$ and placed on a wire rack until dry. The dry discs were then placed individually in sterile Gelman $4.7-\mathrm{cm}$ microbiological dishes, each containing a 4.25 -cm-diameter filter paper. Five second instars of the imidacloprid-resistant strain were placed on to each leaf disc, and the dish was covered. Dishes were transferred to a holding room $\left(25^{\circ} \mathrm{C}, 65 \% \mathrm{RH}\right.$, and a photoperiod of 24:0 [L:D] h) where insects were allowed to feed for $48 \mathrm{~h}$ and then transferred to covered waxed paper cups containing untreated potato foliage. Percentage of mortality of larvae was recorded $96 \mathrm{~h}$ after the start of the experiment.

In synergism tests, $\mathrm{PBO}$ or DEF was applied to second instars with a Potter spray tower (Burkard 
Scientific Ltd., Uxbridge, United Kingdom) before exposure to leaf discs dipped in novaluron. Preliminary tests determined the maximum concentrations of synergists that caused no mortality of second instars. These concentrations, 100 and 500 ppm for PBO and DEF, respectively, were used in bioassays. Insects were placed on moistened filter paper in $90-\mathrm{mm}$ glass petri dishes and placed in the Potter spray tower. The dorsal surface of the insects was sprayed with $5 \mathrm{ml}$ of PBO or DEF. Treated insects were then exposed to novaluron- or imidacloprid-treated leaf discs for $96 \mathrm{~h}$, as described above.

For each insecticide, at least three separate series of bioassays were conducted to give a minimum of 60 larvae (three bioassays $\times 4$ replicates/bioassay $\times 5$ larvae/replicate) per concentration. A minimum of seven concentrations was used to generate regression lines. Concentration-mortality regression lines were generated for each insecticide by probit analysis (SAS Institute 2001). Differences between lethal concentration (LC) values were considered significant if the 95\% confidence limits (CL) did not overlap (Finney 1952)

Persistence of Biological Activity. Microplots (2.25 by $0.9 \mathrm{~m}$ ) consisting of a sandy clay loam soil were established at the SCPFRC-London. Ten potato seed pieces in a single row with 20 -cm spacing were planted per plot. When plants were $40-50 \mathrm{~cm}$ in height $(\approx 6 \mathrm{wk}$ after planting), randomly selected trifoliate leaves were tagged with colored paper clips to ensure that foliage removed for subsequent bioassays (described below) was actually exposed to insecticide during application. Insecticides were applied (900 liter/ha) by using a hand-held, $\mathrm{CO}_{2}$ pressurized $\mathrm{R} \& \mathrm{D}$ plot sprayer (R\&D Sprayers, Opelousas, LA) fitted with a single D- 4 orifice disc and a \#25 swirl plate. Microplots were treated once with 1) novaluron (Rimon $10 \mathrm{EC}$ ) at $25 \mathrm{~g}(\mathrm{AI}) / \mathrm{ha} ; 2)$ novaluron at $50 \mathrm{~g}(\mathrm{AI}) / \mathrm{ha} ; 3)$ imidacloprid (Admire $240 \mathrm{~F}$ ) at $48 \mathrm{~g}(\mathrm{AI}) / \mathrm{ha}$; or 4 ) untreated. Experimental treatments were replicated three times in a randomized complete block design.

Persistence of biological activity of each insecticide on tagged potato leaves was measured by bioassay with leaf discs, as described above. In 2003, potato leaves were harvested from each microplot $0,1,3,5$, $7,10,12,14,17,21$, and $28 \mathrm{~d}$ after treatment. In 2004 , leaves were harvested $0,2,5,7,9,12,15,20,29$, and $35 \mathrm{~d}$ after treatment. On each collection date, three leaves from each microplot were placed in clean, labeled plastic containers and transferred promptly to the laboratory. In total, 45 second instars (five larvae per bioassay $\times 3$ bioassays per plot $\times 3$ plots per treatment) were tested for each treatment on each sample day. Percentage of mortality of larvae was recorded after $120 \mathrm{~h}$. Logistic regressions were conducted to determine the effect of exposure time of foliage in the field on larval mortality for the different treatments. Comparisons of percentage of mortality between treatments on a given day were done by analysis of the variance (ANOVA) of arcsine-transformed data and means separation by the Tukey test at $\alpha=0.05$ (SAS
Institute 1997). Untransformed data are presented in Results.

Survey of Susceptibility to Novaluron. Residual leaf-dip bioassays conducted on second instars of the susceptible strain were used to determine the optimal diagnostic dose for novaluron (Rimon $10 \mathrm{EC}$ ). The $\mathrm{LC}_{98}$ generated from the dose-mortality regression at $120 \mathrm{~h}$ (2.38 ppm) was chosen as the diagnostic dose (Cutler et al. 2005). Insects from each population were exposed to the novaluron diagnostic dose by using a residual leaf-dip bioassay. Trifoliate potato leaves of similar size were cut from potato plants and brought to the laboratory for bioassay. Leaves were immersed in $2.38 \mathrm{ppm}$ novaluron for $\approx 6 \mathrm{~s}$ and placed on wire racks until dry. The petiole of each leaf was inserted into a floral water pick (Sproule Enterprises Ltd., Mississauga, Ontario, Canada) containing reverse-osmosis water to maintain freshness. The sharp tip of the water pick was pushed out through the bottom of a disposable 230-ml foam cup, leaving the treated leaves upright in the cup. Five second instars were placed on the foliage in each cup. The cups were covered with a glass petri dish lids and transferred to a holding room $\left(25^{\circ} \mathrm{C}, 65 \% \mathrm{RH}\right.$, and a photoperiod of $24: 0$ [L:D] h). After $48 \mathrm{~h}$, the larvae from each cup were transferred to clean waxed paper cups, given untreated potato foliage, covered with a glass petri lid, and returned to the holding room. Larval mortality in each cup was recorded after $120 \mathrm{~h}$. Insects were considered alive if they responded to probing with a blunt needle. At least three separate series of bioassays were conducted, giving a minimum of 60 larvae (three bioassays $\times 4$ replicates per bioassay $\times 5$ larvae per replicate) per population at the diagnostic dose. Control mortality (never $>10 \%$ ) was corrected using Abbott's formula (Abbott 1925). Comparisons of percentage of mortality among larvae from different provinces were done by ANOVA of arcsine-transformed data and a Dunnett's test $(\alpha=0.05)$ to compare mortality to the susceptible (control) population (SAS Institute 1997). We considered populations susceptible if the average mortality at the diagnostic dose was $\geq 90 \%$, moderately susceptible if $\geq 75 \%$ and $<90 \%$, problematic if $\geq 50 \%$ and $<75 \%$, and resistant if mortality fell below $50 \%$.

\section{Results and Discussion}

Better Colorado potato beetle management could occur with IPM strategies that curb resistance development by decreasing reliance on insecticides (Cloutier et al. 2002). Although a cornerstone of IPM is the use of selective, biorational compounds that spare nontarget beneficial insects, a lack of selective insecticides has impeded the full development of Colorado potato beetle IPM. Laboratory and field studies have previously demonstrated the potential of novaluron in Colorado potato beetle IPM programs (Malinowski and Pawinska 1992; Linduska et al. 2001, 2002; Sewell and Alyokhin 2003; Cutler et al. 2004, 2005). However, given this pest's extraordinary ability to evolve insecticide resistance it is important to evaluate the risks 
Table 1. Toxicity of novaluron, with and without synergists (PBO and DEF) and imidacloprid to L. decemlineata second instars of insecticide-susceptible and imidacloprid-resistant strains

\begin{tabular}{|c|c|c|c|c|c|c|c|c|c|}
\hline Insecticide & Strain & Synergist $^{a}$ & $n$ & $\begin{array}{c}\text { Slope } \\
( \pm \text { SEM })\end{array}$ & $\begin{array}{c}\mathrm{LC}_{50} \\
(95 \% \mathrm{CL})^{(\mathrm{ppm})}\end{array}$ & $\begin{array}{c}\mathrm{LC}_{95} \\
(95 \% \mathrm{CL})^{(\mathrm{ppm})}\end{array}$ & $\chi^{2}$ & $\begin{array}{l}\text { Resistance } \\
\text { ratio }^{b}\end{array}$ & $\begin{array}{c}\text { Synergism } \\
\text { ratio }^{c}\end{array}$ \\
\hline Novaluron & Susceptible $^{d}$ & & 1190 & $2.49(0.31)$ & $0.61(0.49-0.73)$ & $2.78(2.00-4.77)$ & 35.62 & & \\
\hline Imidacloprid & Susceptible $^{d}$ & & 925 & $2.23(0.25)$ & $0.13(0.11-0.15)$ & $0.69(0.50-1.12)$ & 4.12 & & \\
\hline Novaluron & Resistant & & 787 & $2.54(0.49)$ & $1.52(1.06-1.86)$ & $6.77(4.93-12.98)$ & 7.37 & 2.5 & \\
\hline Imidacloprid & Resistant & & 688 & $2.66(0.53)$ & $0.57(0.43-0.71)$ & $2.36(1.59-5.55)$ & 0.30 & 4.4 & \\
\hline Novaluron & Resistant & $\mathrm{PBO}$ & 723 & $1.47(0.29)$ & $0.99(0.65-1.37)$ & $12.89(6.46-56.21)$ & 0.64 & 1.6 & 1.5 \\
\hline Novaluron & Resistant & DEF & 988 & $3.26(0.51)$ & $0.39(0.29-0.49)$ & $1.26(0.97-1.89)$ & 1.04 & 0.6 & 3.9 \\
\hline
\end{tabular}

${ }^{a}$ Synergists were applied with a Potter spray tower before exposure to treated foliage for $96 \mathrm{~h}$.

${ }^{b} \mathrm{LC}_{50}$ of resistant strain/ $\mathrm{LC}_{50}$ of susceptible strain.

${ }^{c} \mathrm{LC}_{50}$ without synergist/ $\mathrm{LC}_{50}$ with synergist.

${ }^{d}$ Data from Cutler et al. (2005)

and mechanisms of resistance development before the extensive application of novaluron in the field.

Using a leaf-dip bioassay, Cutler et al. (2005) found that the 96-h $\mathrm{LC}_{50}$ values for novaluron and imidacloprid for second instars of the susceptible strain were 0.61 and $0.13 \mathrm{ppm}$, respectively (Table 1 ). In the current study, the imidacloprid $96-\mathrm{h} \mathrm{LC}_{50}$ for second instars of the resistant strain was $0.57 \mathrm{ppm}$ (Table 1), approximately four-fold that of the susceptible strain, but considerably less than the 91-fold imidacloprid resistance for adults of this strain originally determined by Grafius and Byrne (personal communication). However, larvae are much more sensitive to imidacloprid than adults (Zhao et al. 2000; Tolman et al. 2002, 2003). Furthermore, bioassays that expose insects through contact and feeding on treated foliage often result in lower lethal concentrations than bioassays using direct topical exposure (ffrench-Constant and Roush 1990; Tolman et al. 2002, 2003). The resistant strain also had low tolerance to novaluron with an $\mathrm{LC}_{50}$ of $1.52 \mathrm{ppm}, 2.5$-fold that of the susceptible strain (Table 1). Although it is difficult to extrapolate laboratory data to a field situation, these results suggest that novaluron could control Colorado potato beetle larvae from imidacloprid-resistant adults. The proposed Canadian label for Rimon 10 EC recommends application of $220-878 \mathrm{ml} / \mathrm{ha}$ (R. C. Everich, personal communication), whereas the U.S. label (Rimon 10 EC is marketed as Rimon 0.83 EC in the United States) recommends application of $630-840 \mathrm{ml} / \mathrm{ha}$. Generally, to ensure good coverage of the plant canopy most insecticides are applied with $\approx 135-450$ liter/ha (OMAF 2004). If one assumed a volume of 350 liter/ ha, the concentration of novaluron in the spray solution when applied at $878 \mathrm{ml} /$ ha would be $878 \mathrm{ml} / \mathrm{ha} \times$ 1 liter $/ 1000 \mathrm{ml} \times 100 \mathrm{~g}(\mathrm{AI}) / 1$ liter $\times 1$ ha/ 350 liter $\times$ 1 liter $/ 1000 \mathrm{~g} \times 1,000,000 \mathrm{ppm}=250.86 \mathrm{ppm}$. Thus, at this application rate and spray volume, the spray solution novaluron concentration would be 37 and 165 times greater than the $\mathrm{LC}_{95}(6.77 \mathrm{ppm})$ and $\mathrm{LC}_{50}(1.52$ ppm), respectively, of the resistant strain reported in Table 1.

Increased efficiency or quantity of mixed function oxidases and esterases has been reported as a mechanism of Colorado potato beetle resistance to organophosphorous insecticides, carbamates, pyrethroids, abamectins (Bishop and Grafius 1996, and references therein), and imidacloprid (Zhao et al. 2000). When PBO, a mixed function oxidase inhibitor, was applied to larvae before exposure to novaluron-treated foliage, there was no significant change in the $\mathrm{LC}_{50}$ value, as indicated by the overlap of the $95 \%$ CL in the novaluron and novaluron + PBO treatments (Table 1). This suggests that, under the conditions of this experiment, elevated levels of mixed function oxidases were not responsible for the higher tolerance to novaluron in the resistant strain. However, application of DEF, an inhibitor of esterases, to the larvae before exposure to the novaluron treated foliage resulted in an $\mathrm{LC}_{50}$ of $0.39 \mathrm{ppm}$, approximately one-quarter the novaluron $\mathrm{LC}_{50}$ in the absence of the synergist (Table 1). This observation suggests that esterase-based detoxification was important in the low-level resistance to novaluron in the resistant strain. Esterase based metabolism also was important for diflubenzuron resistance in the red flour beetle, Tribolium castaneum (Herbst) (Ishaaya and Klein 1990); the noctuid Spodoptera littoralis (Boisduval) (Ishaaya and Degheele 1988); and the omnivorous leafroller Platynota sultana Walsingham (Granett and Hejazi 1983). However, mixed function oxidases and conjugation were more important mechanisms of resistance to diflubenzuron in the house fly, Musca domestica L. (Cerf and Georghiou 1974, Oppenoorth and Van Der Pas 1977, Chang 1978), and the boll weevil, Anthonomus grandis grandis Boheman (Chang and Stokes 1979), suggesting that mechanisms of detoxification of benzoylphenyl ureas are diverse and vary among different insect species. Although organophosphorous-, carbamate-, and organochlorine-resistant $M$. domestica showed crossresistance with diflubenzuron (Cerf and Georghiou 1974, Oppenoorth and Van Der Pas 1977), Ishaaya et al. (2003) concluded that likelihood of cross-resistance between novaluron and nonbenzoylphenyl urea insecticides was low.

Although persistent biological activity may provide prolonged pest control and offer flexible timing of applications to minimize impacts on natural enemies, persistence has been cited as an important factor in the evolution of insecticide resistance in Colorado potato beetle (Roush 1989, Roush and Tingey 1992, Follet et al. 1993) and other insects such as the horn fly, Hematobia irritans (L.) (Sparks et al. 1985, Roush et al. 1986). Persistent insecticidal activity prolongs 

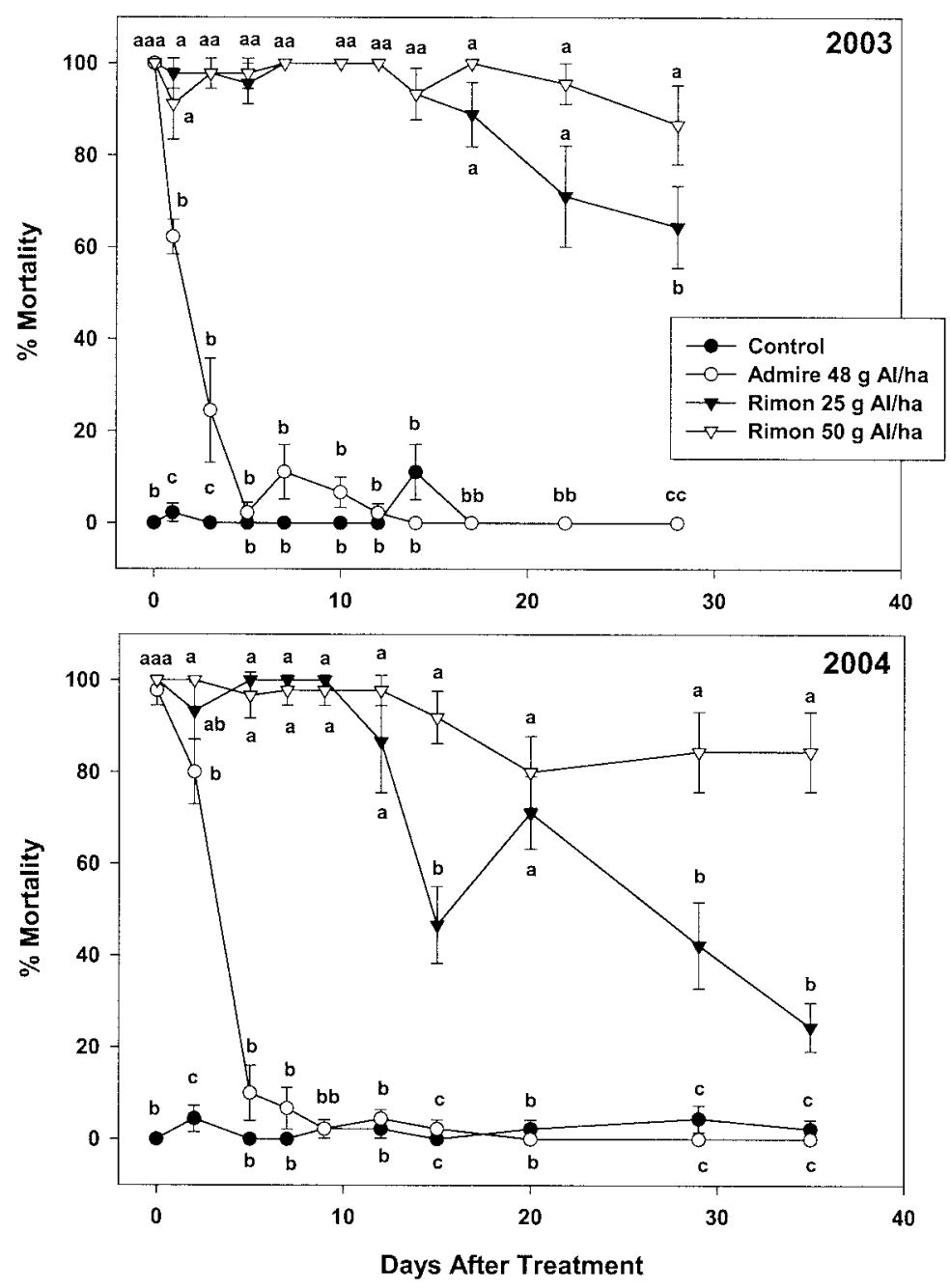

Fig. 1. Mean $\pm 95 \%$ CL percentage of mortality of laboratory reared L. decemlineata second instars $120 \mathrm{~h}$ after exposure to untreated or treated (imidacloprid [Admire $240 \mathrm{~F}$ ] or novaluron [Rimon $10 \mathrm{EC}$ ]) potato foliage. Insecticides were applied in the field and treated foliage was transferred to the laboratory for bioassay. Insects were exposed to treated foliage for $48 \mathrm{~h}$ and thereafter fed untreated foliage for $72 \mathrm{~h}$. For each sample date, means with the same letter for a given day after treatment are not significantly different $(P \leq 0.05$, Tukey test).

selection for resistant individuals and eliminates susceptible homozygotes from a population, thereby reducing the number of susceptible offspring in subsequent generations. In the current study, the biological activity of foliar applications of Rimon 10 EC was very persistent (Fig. 1). In 2003, there was no significant effect of time on second instar mortality over the entire experiment for the Rimon $50 \mathrm{~g}(\mathrm{AI}) /$ ha treatment $\left(\chi^{2}=5.82, \mathrm{df}=4, P=0.21\right)$; just as many larvae died after eating foliage $28 \mathrm{~d}$ after treatment $(87 \%)$ as after $0 \mathrm{~d}$ after treatment (100\%). The Rimon $50 \mathrm{~g}$ (AI) / ha treatment also was very persistent in 2004 . Although second instar mortality decreased significantly $15 \mathrm{~d}$ after treatment $\left(\chi^{2}=22.60, \mathrm{df}=5, P=\right.$ $0.0002)$, there was no significant change between 15 and $35 \mathrm{~d}$ after treatment $\left(\chi^{2}=6.07, \mathrm{df}=5, P=0.30\right)$, when mortality ranged from 80 to $92 \%$ (Fig. 1). The biological activity of the Rimon $25 \mathrm{~g}$ (AI)/ha treatment was less than that of the Rimon $50 \mathrm{~g}$ (AI)/ ha treatment in both 2003 and 2004. Nonetheless, percentage of mortality of second instars decreased significantly for the Rimon $25 \mathrm{~g}$ (AI) / ha treatment only after $22 \mathrm{~d}$ after treatment in $2003\left(\chi^{2}=6.47, \mathrm{df}=4\right.$, $P=0.039)$, and after $15 \mathrm{~d}$ after treatment in 2004 $\left(\chi^{2}=8.26, \mathrm{df}=5, P=0.041\right)$. The biological activity of the Admire $48 \mathrm{~g}$ ( $\mathrm{AI}) /$ ha treatment was far less persistent than that of either novaluron treatment (Fig. 1). In 2003, mortality of second instars exposed to Admire $48 \mathrm{~g}$ (AI)/ha-treated foliage had fallen significantly by $1 \mathrm{~d}$ after treatment $\left(\chi^{2}=24.95, \mathrm{df}=\right.$ $5, P<0.0001$ ), whereas in 2004 mortality of second instars had significantly decreased by $5 \mathrm{~d}$ after treatment $\left(\chi^{2}=29.03, \mathrm{df}=5, P<0.0001\right)$. Mortality of second instars exposed to untreated potato foliage 


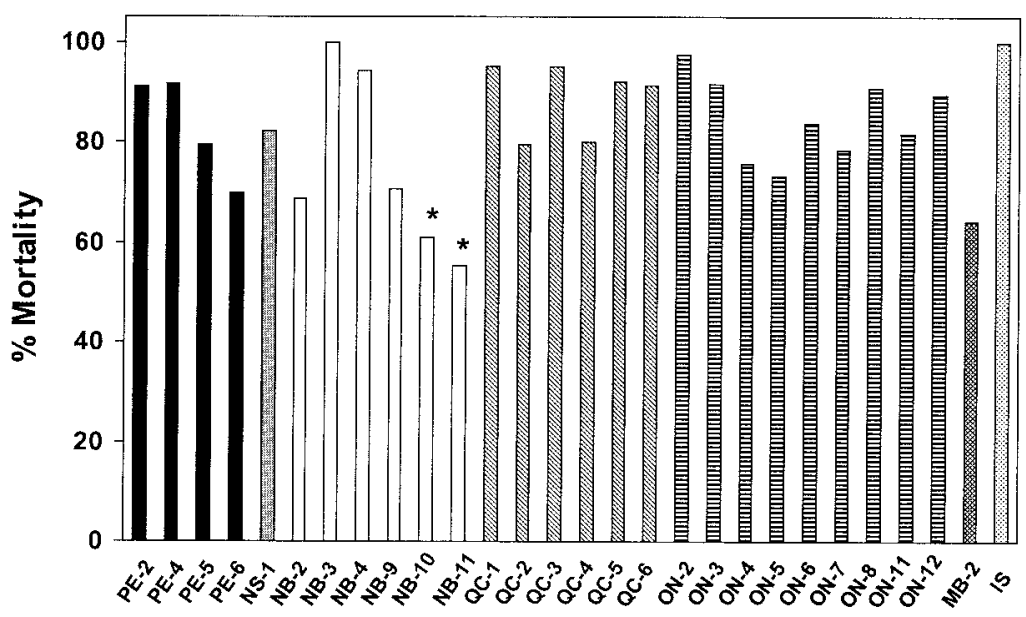

Population

Fig. 2. Susceptibility of $L$. decemlineata second instars from populations from different Canadian provinces (PE, Prince Edward Island; NS, Nova Scotia; NB, New Brunswick; QC, Quebec; ON, Ontario; and MB, Manitoba) to a novaluron diagnostic dose (2.38 ppm $=\mathrm{LC}_{98}$ of a laboratory-reared insecticide-susceptible strain), 2003. Bars with an asterisk (*) above them are significantly different from the laboratory-reared insecticide-susceptible (IS) strain $(P \leq 0.05$, Dunnett's test).

from control plots was very low in both 2003 and 2004 (Fig. 1) with no significant mortality over the course of the experiments (2003: $\chi^{2}=0.27, \mathrm{df}=2, P=0.87$; and 2004: $\chi^{2}=0.73$, df $=1, P=0.39$ ).

The persistent biological activity of foliar-applied novaluron suggests that the selection pressure for novaluron-resistant Colorado potato beetle could be intense. In 2003 and 2004, the experiments had to be terminated after 28 and $35 \mathrm{~d}$, respectively, due to severe leafhopper damage to the potato foliage. Considering that in both years $80 \%$ of second instars were still dying after feeding on Rimon $50 \mathrm{~g}$ (AI) / ha-treated foliage at the end of the experiment, it is likely that the insecticidal activity of novaluron would have extended beyond this time. Furthermore, the proposed label rates for Rimon $10 \mathrm{EC}$ for Colorado potato beetle management in Canada and the United States are 22-87.5 and 63-84 g (AI)/ha, respectively. Because reapplication is recommended after $7-14 \mathrm{~d}$ to protect new growth, potato growers using novaluron may therefore apply the product twice as often at a rates 1.75 -fold that used in this study, exposing larvae to toxic doses over a long time.

In the survey of susceptibility to a novaluron diagnostic dose, the Colorado potato beetle populations were found to differ significantly in their response to the novaluron diagnostic dose $(F=3.30, \mathrm{df}=27, P=$ 0.0003) (Fig. 2). However, the Dunnett's test found only the New Brunswick-10 and New Brunswick-11 populations to be significantly less susceptible than the laboratory susceptible strain (Fig. 2). Although none of the populations recorded $<50 \%$ mortality, seven of 27 field populations were considered potentially problematic with $<75 \%$ mortality recorded. Four of these populations were collected in New Brunswick, and one each from Prince Edward Island, Ontario, and Manitoba. Tolman et al. (2003) found that in the majority of cases, these same populations exhibited reduced susceptibility to imidacloprid, lambda-cyhalothrin, spinosad, and azinphos-methyl, suggesting mechanisms that reduced susceptibility to these compounds also may have resulted in reduced susceptibility to novaluron. In a survey of susceptibility of Colorado potato beetle populations from western provinces, Noronha et al. (2002) also found high prevalence of insecticide resistance in Manitoba populations. They attributed this to extensive insecticide use to control growing Colorado potato beetle populations that followed a rapid increase in potato acreage in Manitoba in the 1990s. Although no Quebec populations recorded $<75 \%$ mortality at the novaluron diagnostic dose (Fig. 2), Tolman et al. (2003) found that the second instars from the moderately susceptible Quebec-4 population (Fig. 2) had only 23, 27, 43, and $68 \%$ mortality when exposed to a diagnostic dose of lambda-cyhalothrin, imidacloprid, spinosad, and azinphos-methyl, respectively. This suggests that novaluron could be an effective alternative to these compounds to control larvae from the Quebec-4 population. Ergo, resistance to conventional insecticides may or may not confer resistance to novaluron. Although the lowest population mortality recorded at the diagnostic dose was 55\% (New Brunswick-11), no significant difference in mortality at the diagnostic dose was found between provinces $(F=1.95, \mathrm{df}=5, P=0.097$ ) (Fig. 2). Eleven of the 27 field populations (two from Prince Edward Island, two from New Brunswick, four from Quebec, and three from Ontario) were susceptible with $90 \%$ mortality at the diagnostic dose (Fig. 2). Nine of the 27 field populations were moderately susceptible to novaluron.

Differences in susceptibility of Colorado potato beetle populations to insecticides are best explained by insecticide use patterns. Rather than evolving in 
isolated areas and spreading geographically, resistance in Colorado potato beetle responds to local selection pressure, resulting in repeated and independent resistance development (Bishop and Grafius 1996). Strong correlations between the frequency of insecticide applications and development of resistance have been reported (Hare 1980, Tisler and Zehnder 1990, Roush et al. 1990). However, because the populations surveyed had never been exposed to novaluron, the variability in susceptibility to the novaluron diagnostic dose must be due to natural variation. This variation is probably the result of preexisting metabolic and excretion mechanisms selected by previous exposure to other insecticides. As indicated above, low novaluron resistance identified in the resistant strain was at least partially due to increased quantities or efficiency of esterases, a mechanism used by Colorado potato beetle in resistance to several other insecticides. Tolman et al. (2003) found many of the Canadian Colorado potato beetle populations used in this study also were highly variable in their susceptibility to spinosad (Tracer $480 \mathrm{SC}$ ), a macrocyclic lactone insecticide registered in Canada in 2003 for Colorado potato beetle management. When exposed to a spinosad diagnostic dose, 34 of 47 populations exhibited $<75 \%$ mortality and $>90 \%$ mortality was found in only five populations (Tolman et al. 2003). Like novaluron, spinosad has a novel mode of action, is considered a reduced-risk product, and may become an important component of Colorado potato beetle management programs. However, because many of the Canadian Colorado potato beetle populations demonstrated tolerance to these novel compounds, the mechanisms necessary for resistance development may already exist at levels sufficient to cause premature control failures.

Colorado potato beetle has evolved resistance to almost every compound used against it in commercial agriculture. Results of this study indicate there is certainly potential for development of resistance to novaluron. Considerable variability in baseline susceptibility to novaluron already exists in Canadian Colorado potato beetle populations and such variability is probably present in potato growing regions of the United States and Europe as well. Esterase detoxification mechanisms and long-term persistence of biological activity are other factors that may be important in novaluron resistance. However, despite these results and Colorado potato beetle's daunting resistance development history, novaluron could play an important role in Colorado potato beetle management programs. Novaluron possesses several important characteristics that may delay resistance development in Colorado potato beetle and other insect pests. First, its mode of action is completely different from that of the commonly used conventional compounds meaning cross-resistance is less likely. Second, its selective properties should allow the survival of natural enemies, thereby providing an additional Colorado potato beetle mortality factor, reducing the need for repeated insecticide applications. Third, the mode of action of novaluron dictates its use against larval stages, which are usually more sensitive to and less capable of developing resistance to insecticides (Roush 1989). Indeed, Hilton et al. (1998) found Colorado potato beetle larvae to be more susceptible than adults to eight different insecticides and Zhao et al. (2000) found that potato beetle larvae are much more sensitive to imidacloprid than adults. In the current study, Colorado potato beetle larvae from adults exhibiting 91-fold resistance to imidacloprid were highly susceptible to novaluron. Fourth, because novaluron is nonsystemic, refugia will exist in new plant growth (barring repeat application), permitting survival of susceptible genotypes and production of susceptible offspring in subsequent generations. Thus, if combined with well-established resistance management practices, including insecticide alternations, field rotations, and biological and cultural control tactics, novaluron could play an important role in Colorado potato beetle management for many years.

\section{Acknowledgments}

We appreciate the cooperation of the numerous growers and government/ extension personnel in collecting Colorado potato beetle from commercial and experimental fields. We thank E. Grafius and A. Byrne (Michigan State University) for providing the imidacloprid-resistant Colorado potato beetle strain, and David Pree (Agriculture and Agri-Food Canada Vineland Station) for providing the DEF. The technical assistance of Evelyn Dell, Teri Dickenson, Jamie McNeil, Eric Roesler, and Jay Whistlecraft is acknowledged. This work was funded by the Natural Sciences and Engineering Research Council of Canada (to G.C.C.), the Ontario Graduate Scholarship program (to G.C.C.), the Ontario Ministry of Agriculture and Food-University of Guelph Plants Program, Agriculture and Agri-Food Canada, the Matching Investment Initiative of Agriculture and Agri-Food Canada, the Ontario Potato Board, Crompton Co./Cie and Makhteshim-Agan of North America.

\section{References Cited}

Abbott, W. S. 1925. A method for computing the effectiveness of an insecticide. J. Econ. Entomol. 18: 265-267.

Bishop, B. A., and E. J. Grafius. 1996. Insecticide resistance in the Colorado potato beetle, pp. 355-377. In P.H.A. Jolivet and M. L. Cox [eds.], Chrysomelidae biology, vol. 1: the classification, phylogeny and genetics. SPB Academic Publishing, Amsterdam, The Netherlands.

Boiteau, G., R. H. Parry, and C. R. Harris. 1987. Insecticide resistance in New Brunswick populations of the Colorado potato beetle (Coleoptera: Chrysomelidae). Can. Entomol. 119: 459-463.

Cabrera, A. R., R. A. Cloyd, and E. R. Zaborski. 2005. Lethal and sub-lethal effects of novaluron (Pedestal) on the soil-dwelling predatory mite, Stratiolaelaps scimitus (Womersley) (Acari: Mesostigmata: Laelapidae), under laboratory conditions. J. Entomol. Sci. 40: 47-53.

Cerf, D. C., and G. P. Georghiou. 1974. Cross-resistance to an inhibitor of chitin synthesis, TH $60-40$, in insecticide resistant strains of the housefly. J. Agric. Food Chem. 22: $1145-1146$.

Chang, S. C. 1978. Conjugation: the major metabolic pathway of ${ }^{14} \mathrm{C}$-diflubenzuron in the house fly. J. Econ. Entomol. 71: 31-39. 
Chang, S. C., and J. B. Stokes. 1979. Conjugation: the major metabolic pathway of ${ }^{14} \mathrm{C}$-diflubenzuron in the boll weevil. J. Econ. Entomol. 72: 15-19.

Cloutier, C., G. Boiteau, and M. S. Geottel. 2002. Leptinotarsa decemlineata (Say), Colorado potato beetle (Coleoptera: Chrysomelidae), pp. 145-152. In P. G. Mason and J. T. Huber [eds.], Biological control programmes in Canada, 1981-2002. CABI Publishing, New York.

Cutler, G. C., C. D. Scott-Dupree, and E. Roesler. 2004. Relative efficacy of novaluron (Rimon 10EC) and imidacloprid (Admire 240F) for control of Colorado potato beetle, Leptinotarsa decemlineata (Say), in potato on sandy soil. 2003 Pest Manag. Res. Rep.-Veg. Spec. Crops, Insect Pests 42: 63-68.

Cutler, G. C., C. D. Scott-Dupree, J. H. Tolman, and C. R. Harris. 2005. Acute and sublethal toxicity of novaluron, a novel chitin synthesis inhibitor, to Leptinotarsa decemlineata (Coleoptera: Chrysomelidae). Pest Manag. Sci. (in press).

ffrench-Constant, R. H., and R. T. Roush. 1990. Resistance detection and documentation: the relative roles of pesticidal and biochemical assays, pp. 4-38. In R. T. Roush and B. E. Tabashnik [eds.], Pesticide resistance in arthropods. Chapman \& Hall, New York

Finney, D. J. 1952. Probit analysis: a statistical treatment of the sigmoid response curve. Cambridge University Press, Cambridge, United Kingdom.

Follet, P. A., G. C. Kennedy, and F. Gould. 1993. REPO: a simulation model that explores Colorado potato beetle (Coleoptera: Chrysomelidae) adaptation to insecticides. Environ. Entomol. 22: 283-296.

Georghiou, G. P. 1986. The magnitude of the resistance problem, pp. 14-43. In National Academy of Sciences [ed.], Pesticide resistance: strategies and tactics for management. National Academy of Sciences, Washington, DC.

Granett, J., and M. J. Hejazi. 1983. Synergism two benzoylphenyl urea insect growth regulators. J. Econ. Entomol. 76: 403-406

Hare, J. D. 1980. Contact toxicities of 10 insecticides to Connecticut populations of Colorado potato beetle. J. Econ. Entomol. 73: 230-231.

Harris, C. R., and H. J. Svec. 1976. Susceptibility of the Colorado potato beetle in Ontario to insecticides. J. Econ. Entomol. 69: 625-629.

Harris, C. R., and H. J. Svec. 1981. Colorado potato beetle resistance to carbofuran and several other insecticides in Quebec. J. Econ. Entomol. 74: 421-424.

Harris, C. R., and S. A. Turnbull. 1986. Contact toxicity of some pyrethroid insecticides, alone and in combination with piperonyl butoxide, to insecticide-susceptible and pyrethroid-resistant strains of the Colorado potato beetle (Coleoptera: Chrysomelidae). Can. Entomol. 118: 11731176 .

Hilton, S. A., J. H. Tolman, D. C. MacArthur, and C. R. Harris. 1998. Toxicity of some insecticides to several life stages of Colorado potato beetle, Leptinotarsa decemlineata (Say). Can. Entomol. 130: 187-194.

Ishaaya, I., and D. Degheele. 1988. Properties and toxicological significance of diflubenzuron hydrolase activity in Spodoptera littoralis larvae. Pestic. Biochem. Physiol. 32: $180-187$.

Ishaaya, I., and M. Klein. 1990. Response of laboratory (susceptible) and field resistant strains of Spodoptera littoralis (Lepidoptera: Nectuidae) to teflubenzuron. J. Econ. Entomol. 83: 59-62.

Ishaaya, I., S. Yablonski, Z. Mendelson, Y. Mansour, and A. R. Horowitz. 1996. Novaluron (MCW-275), a novel benzoylphenyl urea, suppressing developing stages of lepidopteran, whitefly and leafminer pests, pp. 1013-1020. In Proceedings of the 1996 Brighton Crop Protection Conference-Pests and Disease, 18-21 November 1996, Brighton, United Kingdom. BCPC Publications, Croydon, United Kingdom.

Ishaaya, I., S. Kontsedalov, D. Mazirov, and A. R. Horowitz. 2001. Biorational agents: mechanisms and importance in IPM and IRM programs for controlling agricultural pests. Proc. Int. Symp. Crop. Protect. Med. Fac. Landbouww. Univ. Gent. 66: 363-374.

Ishaaya, I., A. R. Horowitz, L. Tirry, and A. Barazani. 2002. Novaluron (Rimon) a novel IGR: mechanism, selectivity and importance in IPM programs. Proc. Int. Symp. Crop. Protect. Med. Fac. Landbouww. Univ. Gent. 67: 617-626.

Ishaaya, I., S. Kontsedalov, and A. R. Horowitz. 2003. Novaluron (Rimon) a novel IGR: potency and cross-resistance. Arch. Insect Biochem. Physiol. 54: 157-164.

Linduska, J. J., M. Ross, B. Abbott, S. Steele, and R. Eastman. 2001. Colorado potato beetle control on potatoes, 2000 . Arthropod Manag. Tests 26: E51.

Linduska, J. J., M. Ross, B. Abbott, S. Steele, R. Ross, and R. Eastman. 2002. Colorado potato beetle control on potatoes, 2001. Arthropod Manag. Tests 27: E69.

Malinowski, H., and M. Pawinska. 1992. Comparative evaluation of some chitin synthesis inhibitors as insecticides against Colorado potato beetle Leptinotarsa decemlineata (Say). Pestic. Sci. 35: 349-353.

McDonald, S. 1976. Evaluation of several new insecticides for the control of Colorado potato beetle and the status of DDT resistance in southern Alberta. J. Econ. Entomol. 69: $659-664$.

Mota-Sanchez, D., M. Whalon, E. Grafius, and R. Hollingworth. 2000. Resistance of Colorado potato beetle to imidacloprid. Resistant Pest Manag.. 11: 31-34.

Noronha, C., G. M. Duke, J. M. Chinn, and M. S. Goettel. 2002. Differential susceptibility to insecticides by Leptinotarsa decemlineata (Coleoptera: Chrysomelidae) populations from western Canada. Phytoprotection 82: 113-121.

Olson, E. R., G. P. Dively, and J. O. Nelson. 2000. Baseline susceptibility to imidacloprid and cross resistance patterns in Colorado potato beetle (Coleoptera: Chrysomelidae) populations. J. Econ. Entomol. 93: 447-458.

OMAF. 2004. Publication 363. Vegetable Production Recommendations 2004-2005. Queen's Printer for Ontario, Toronto, Ontario, Canada.

Oppenoorth, F. J., and L.J.T. Van Der Pas. 1977. Crossresistance to diflubenzuron in resistant strains of housefly Musca domestica. Entomol. Exp. Appl. 21: 217-228.

Roush, R. T. 1989. Designing resistance management programs: how can you choose? Pestic. Sci 26: 423-441.

Roush, R. T., and W. M. Tingey. 1992. Evolution and management of resistance in the Colorado potato beetle, Leptinotarsa decemlineata, pp. 61-74. In G. W. Zehnder, M. L. Powelson, R. K. Jansson, and K. V. Raman [eds.], Resistance 91: achievements and developments in combating pesticide resistance. Elsevier Applied Science, London,United Kingdom.

Roush, R. T., R. L. Combs, T. C. Randolph, J. McDonald, and J. A. Hawkins. 1986. Inheritance and effective dominance of pyrethroid resistance in the horn fly (Diptera: Muscidae). J. Econ. Entomol. 79: 1178-1182.

Roush, R. T., C. W. Hoy, D. N. Ferro, and W. M. Tingey. 1990. Insecticide resistance in Colorado potato beetle (Coleoptera: Chrysomelidae): influence of crop rotation and insecticide use. J. Econ. Entomol. 83: 315-319.

SAS Institute. 1997. JMP IN version 3.2. SAS Institute, Cary, NC. 
SAS Institute. 2001. SAS system for Windows, release 8.2. SAS Institute, Cary, NC.

Sewell, G. H., and A. Alyokhin. 2003. Control of Colorado potato beetle on potato, 2002. Arthropod Manag. Tests 28: E63.

Sparks, T. C., S. S. Quisenberry, J. A. Lockwood, R. L. Byford, and R. T. Roush. 1985. Insecticide resistance in the horn fly, Haematobia irritans. J. Agric. Entomol. 2: 217-233.

Tisler, A. M., and G. W. Zehnder. 1990. Insecticide resistance in the Colorado potato beetle (Coleoptera: Chrysomelidae) on the eastern shore of Virginia. J. Econ. Entomol. 83: 666-671.

Tolman, J. H., S. A. Hilton, J. W. Whistlecraft, and D. C. MacArthur. 2002. Survey of susceptibility of representative Canadian populations of Colorado potato beetle, Leptinotarsa decemlineata (Say) to selected insecticides: Admire 240F (imidacloprid), Matador 120EC (lambda-cyhalothrin) and Success 480SC (spinosad). Annual Research Report (FY 2002-2003) to Ontario Potato Board (AAFC M.I.I. Project No. A03027).
Tolman, J. H., J. W. Whistlecraft, and J. R. McNeil. 2003. Survey of susceptibility of representative Canadian populations of Colorado potato beetle, Leptinotarsa decemlineata (Say) to selected insecticides: Admire $240 \mathrm{~F}$ (imidacloprid), Matador 120EC (lambda-cyhalothrin), Tracer 480SC (spinosad) and Guthion 240SC (azinphosmethyl). Annual Research Report (FY 2003-2004) to Ontario Potato Board (MII Project No. A03027).

Whalon, M., D. Mota-Sanchez, and L. Duynslager. 2004. The database of arthropod resistance to pesticides. http:/ / www.pesticideresistance.org/DB/index.html.

Zhao, J., B. A. Bishop, and E. J. Grafius. 2000. Inheritance and synergism of resistance to imidacloprid in the Colorado potato beetle (Coleoptera: Chrysomelidae). J. Econ. Entomol. 93: 1508-1514.

Received 25 February 2005; accepted 12 June 2005. 